\title{
Upaya Meningkatkan Hasil Belajar Passing Bawah Bola Voli Melalui Model Pembelajaran Kooperatif Tipe Team Games Tournament
}

\section{Efforts to Improve Volleyball Bottom Passing Learning Outcomes Through Cooperative Learning Models of Team Game Tournament Type}

\author{
Dian Pujianto*, Bayu Insansityo, Syafrial \\ Pendidikan Jasmani, Universitas Bengkulu, Jl. WR. Supratman, Kandang Limun, Kec. Muara Bangka Hulu, \\ Sumatera, Bengkulu, 38371, Indonesia \\ e-mail:dianpujianto@unib.ac.id, bayuinsanistyo@unib.ac.id, syafrial@unib.ac.id
}

\begin{abstract}
Abstrak
Penelitian ini bertujuan untuk mengetahui sejauh mana efektivitas model pembelajaran kooperatif tipe team games tournament dalam meningkatkan hasil belajar passing bawah bola voli. Jenis penelitian yang digunakan adalah penelitian tindakan kelas. Subyek penelitian ini adalah mahasiswa pendidikan jasmani semester 3 yang mengikuti perkuliahan bola voli dan dosen pengampu mata kuliah bola voli. Hasil penelitian menunjukkan data pada pra siklus mahasiswa yang memperoleh nilai 70 ke atas ada 15,9\% mahasiswa dan yang memperoleh nilai di bawah 70 ada $84,1 \%$ mahasiswa. Pada akhir siklus 1 mahasiswa yang memperoleh nilai di atas 70 ada 29,5\% dan yang memperoleh nilai di bawah 70 ada 70,5\%. Pada akhir siklus 2 mahasiswa yang memperoleh nilai di atas 70 telah tercapai $100 \%$. Sehingga dapat disimpulkan bahwa model pembelajaran Kooperatif Tipe Team Games Tournament dapat meningkatkan hasil belajar passing bawah bola voli mahasiswa.
\end{abstract}

Kata Kunci: Bola voli, Passing Bawah, dan Kooperatif.

\section{Abstract}

This study aims to determine the effectiveness of the team game tournament type cooperative learning model in improving volleyball forearm passing learning outcomes. The type of research used is classroom action research. The subjects of this study were $3 \mathrm{rd}$ semester physical education students who attended volleyball lectures and volleyball lecturers. The results showed that in the pre-cycle data, there were $15.9 \%$ students who scored 70 and above and $84.1 \%$ of students who scored below 70 scored. At the end of cycle 1, students who scored above 70 were $29.5 \%$ and those who scored below 70 were 70.5\%. At the end of cycle 2, students who scored above 70 had achieved 100\%. So it can be concluded that the Team Games Tournament Type Cooperative learning model can improve student volleyball forearm passing learning outcomes.

Keywords: Volley Ball, Fore arm Pass, Cooperative

*corresponding author:

\section{Artikel Info:}

Submitted: 29/09/2021

Revised : 28/10/2021

Accepted : 06/11/2021

Published: 15/11/2021 


\section{A. Pendahuluan}

Mahasiswa Prodi Pendidikan Jasmani dan Kesehatan dididik untuk menjadi seorang tenaga pendidik Pendidikan Jasmani dan Kesehatan yang profesional (Malik \& Rubiana, 2019). Sehingga dalam kurikulum program studi pendidikan jasmani telah disusun sedemikian rupa agar mahasiswa mempunyai pengalaman belajar yang optimal selama masa studi di program studi pendidikan jasmani (Mustafa \& Dwiyogo, 2020). Selain itu tenaga pendidik di program studi pendidikan jasmani merupakan tenaga pendidik yang telah diseleksi dan berkualifikasi pendidikan magister (S2) pada bidang-bidang ilmu yang berkaitan dengan pendidikan jasmani (Kanca, 2017).

Demikian juga dengan mahasiswa pendidikan jasmani yang merupakan mahasiswa pilihan dari banyaknya calon mahasiswa yang berminat masuk ke program studi pendidikan jasmani (Suhesti Herin, 2020). Mahasiswa telah diseleksi secara: pertama fisik, yaitu kondisi fisik dari calon mahasiswa apakah telah sesuai dengan persyaratan yang ada atau tidak memenuhi. Kedua secara kognitif, apakah mahasiswa mempunyai pengetahuan yang telah memenuhi standar minimum yang disyaratkan di program studi pendidikan jasmani. Ketiga secara psikomotor, calon mahasiswa diuji keterampilan geraknya, untuk mengetahui kemampuan gerak dasar dari calon mahasiswa (Oktariana \& Hardiyono, 2020). Sehingga, jika disimpulkan bahwa adanya kurikulum yang terus diperbaharui untuk penyesuaian dengan kebutuhan lapangan kerja, adanya tenaga pendidik yang berkompeten dengan bidangnya, kemudian input mahasiswa yang telah disesuaikan dengan kebutuhan program studi, maka diharapkan kemampuan, keterampilan, dan pengetahuan mahasiswa akan mampu untuk menguasai proses perkuliahan dengan baik dan lancar.

Akan tetapi pada kenyataannya masih ada beberapa mahasiswa yang tidak mampu mengikuti proses perkuliahan dengan baik atau sesuai dengan aturan. Hal ini terlihat pada mata kuliah bola voli pada semester 3 tahun lalu, dimana masih banyak mahasiswa yang belum memahami tentang peraturan bola voli, sistem pertandingan bola voli, teknik dasar passing bawah bola voli dan perwasitan bola voli. Padahal mereka adalah calon pendidik yang harus siap untuk mentransferkan ilmunya pada anak didiknya pada suatu saat nanti. Untuk itu perlu suatu pendekatan kepada mahasiswa agar mahasiswa dengan cepat mampu menguasai teknik dasar passing bawah sebagai salah satu teknik yang harus dikuasai dalam permainan bola voli serta memahami peraturan, pertandingan, dan perwasitan Bola voli. Teknik dasar passing 
bawah bola voli tidak dapat dipelajari hanya dengan membaca buku saja, perlu pengalaman langsung dan salah satu bentuk model pembelajaran dengan pengalaman langsung adalah model pembelajaran kooperatif tipe team games tournament. Menurut (Metzler, 2017), tipe pembelajaran kooperatif team games tournament bercirikan bahwa setiap mahasiswa masuk dalam sebuah tim, tim tersebut diberikan tugas untuk berlatih dan belajar dalam kurun waktu tertentu dan kemudian setiap tim akan dipertandingkan untuk mencari pemenang (Masi \& Wasak, 2020). Dari proses pembelajaran ini muncul kompetisi pada setiap tim untuk menjadi yang terbaik. Sehingga setiap tim akan berusaha untuk berlatih dan belajar dengan sebaik mungkin. Dan ini diharapkan akan memberikan dampak pada hasil belajar mahasiswa untuk mampu secara klasikal lulus dengan predikat nilai B sebanyak 99\%.

\section{B. Metode Penelitian}

Penelitian ini adalah penelitian tindakan kelas. Karena akan memberikan sebuah perlakuan pada sebuah kelas yang memiliki hambatan dalam sebuah proses pembelajaran, dan tindakan ini berupaya untuk memperbaiki kondisi proses pembelajaran tersebut.

Penelitian tindakan kelas memiliki 4 prosedur penting yang harus dilaksanakan yaitu (Pujianto \& Insanistyo, 2013);

\section{Perencanaan}

Pada tahap ini menjelaskan terkait apa, mengapa, kapan, di mana oleh siapa dan bagaimana tindakan akan dilasanakan. Jadi pada tahap ini peneliti menyusun rancangan penelitian dengan terlebih mengidentifikasi masalah kemudian membuat solusinya. Dalam perencanaan ini peneliti mengajak teman sejawat untuk mengamati dan melaksanakan tindakan.

\section{Pelaksanaan}

Pada tahap pelaksanaan ini merupakan tahap pelaksanaan dari rancangan yang telah dibuat oleh peneliti. Pada tahap ini dosen harus mengingat semua rancangan tindakan yang akan diberikan kepada mahasiswa sehingga hasil dari penelitian tidak akan melenceng dari apa yang akan diharapkan.

\section{Pengamatan}

Pada proses pengamatan dilaksanakan pada saat dosen memberikan tindakan kepada mahasiswa. Pengamatan dilakukan oleh peneliti, dosen pemberi tindakan, dan teman sejawat. Hal-hal yang diamati adalah proses pemebelajaran, aktivitas dosen dan aktivitas mahasiswa dalam perkuliahan.

4. Refleksi

Pada tahap ini adalah proses mengevaluasi tindakan yang telah dilaksankan oleh dosen. Penilai adalah 
Upaya Meningkatkan Hasil Belajar Passing Bawah Bola Voli Melalui Model Pembelajaran Kooperatif Tipe

Team Games Tournament

E-ISSN: 2722-3450 P-ISSN: 2775-3808

observer yang telah ditugaskan untuk mengamati proses pembelajaran. Hasil pengamatan ini akan di bahas oleh peneliti untuk didapat suatu kesimpulan untuk menghentikan atau merencanakan tindakan selanjutnya (Gall et al., 2003).

Tahap selanjutnya adalah pengumpulan data, data dikumpulkan dengan tes, yaitu tes passing bawah bola voli. Tes ini menggunakan instrumen Brady Ball tes (Miller, 2010). Teknik analisis data menggunakan rumus prosentase;

$$
\mathrm{Kb}=\frac{N S}{N} \times 100 \%
$$

$\mathrm{Kb}=$ persentase ketuntasan belajar klasikal.

NS = jumlah siswa yang mencapai KKM.

$\mathrm{N}$ = Jumlah seluruh siswa

\section{Hasil dan Pembahasan}

Hasil dari penelitian ini diperoleh dari tes awal passing bawah bola voli. Sebelum proses perkuliahan dimulai mahasiswa diberikan tes passing bawah bola voli, kemudian setelah siklus pertama selesai mahasiswa diberikan lagi tes passing bawah bola voli, tes diberikan lagi setelah siklus kedua selesai. Adapun data dari hasil pre tes pra siklus adalah sebagai berikut:

Tabel. 1 Data Pre Tes Passing Bawah Bola voli

\begin{tabular}{ccccc}
\hline No & Skor & Rentang Nilai & Frekuensi & $(\boldsymbol{\%})$ \\
\hline 1. & $46-60$ & $80-100$ & - & 0 \\
\hline 2. & $31-45$ & $70-79,9$ & 7 & 15,9 \\
\hline 3. & $16-30$ & $60-69,9$ & 20 & 45,5 \\
\hline 4. & $0-15$ & $\begin{array}{c}59,9-\mathrm{ke} \\
\text { bawah }\end{array}$ & 17 & 38,6 \\
\hline \multicolumn{5}{c}{ Jumlah } \\
\hline
\end{tabular}

Dari data tabel 1 dapat diketahui hasil pre test passing bawah bola voli mahasiswa yaitu; ada 17 mahasiswa atau $38,6 \%$ mahasiswa memiliki nilai di bawah 60. Ada 20 mahasiswa atau $45,5 \%$ mahasiswa memiliki nilai diantara 60 sampai dengan 69,9 dan ada 7 mahasiswa atau $15,9 \%$ mahasiswa memiliki nilai diantara 70 sampai dengan 79,9. Sehingga dari data di atas dapat disimpulkan bahwa mahasiswa rata-rata memiliki nilai di bawah nilai 70, yaitu sebanyak 37 mahasiswa atau $84,1 \%$ mahasiswa belum mencapai nilai 70 atau kategori nilai B dan hanya 7 mahasiswa atau 15,9\% mahasiswa yang memperoleh nilai diantara 70 sampai dengan 79,9 atau kategori B.

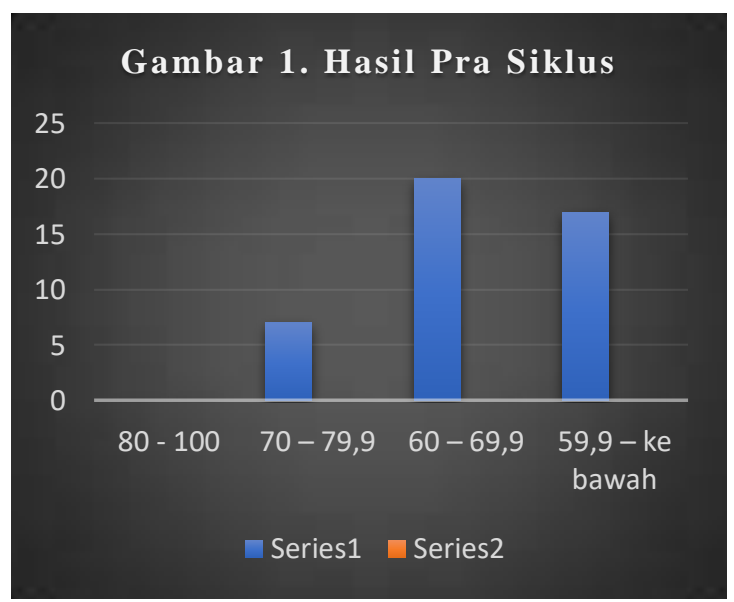

Berikut ini hasil belajar passing bawah setelah siklus pertama selesai:

Tabel. 2 Data Siklus 1 Passing Bawah Bola voli

\begin{tabular}{|c|c|c|c|c|}
\hline No & Skor & Rentang Nilai & Frekuensi & $(\%)$ \\
\hline 1. & $46-60$ & $80-100$ & 3 & 6,8 \\
\hline 2. & $31-45$ & $70-79,9$ & 10 & 22,7 \\
\hline 3. & $16-30$ & $60-69,9$ & 20 & 45,5 \\
\hline \multirow[t]{2}{*}{4.} & $0-15$ & $59,9-$ ke bawah & 11 & 25 \\
\hline & & Jumlah & 44 & 100 \\
\hline
\end{tabular}


Berdasarkan tabel 2, dapat diketahui adanya peningkatan dari pre tes pada saat pra siklus. Pada saat pra siklus ada 7 mahasiswa yang memperoleh nilai di atas 70. Dan pada saat akhir siklus 1 diperoleh data mahasiswa yang memperoleh nilai di atas 70 ada 13 mahasiswa atau 29,5\% mahasiswa telah mencapai kriteria ketuntasan minimal dan masih ada $70,5 \%$ mahasiswa belum mencapai kriteria ketuntasan minimal. Berdasarkan data ini, walaupun belum semua mahasiswa tuntas, tetapi telah ada peningkatan hasil belajar passing bawah mahasiswa setelah diberikan model pembelajaran Kooperatif Team Games Tournament.

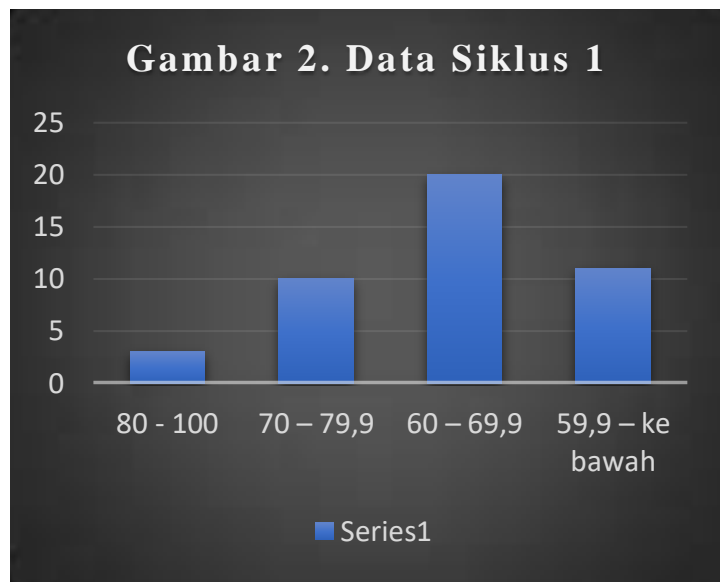

Selanjutnya data hasil siklus 2 , adalah sebagai berikut:

Tabel. 3 Data Siklus 2 Passing Bawah Bola voli

\begin{tabular}{ccccc}
\hline No & Skor & Rentang Nilai & Frekuensi & $\mathbf{( \% )}$ \\
\hline 1. & $46-60$ & $80-100$ & 10 & 22,7 \\
\hline 2. & $31-45$ & $70-79,9$ & 34 & 77,3 \\
\hline 3. & $16-30$ & $60-69,9$ & - & 0 \\
\hline 4. & $0-15$ & $\begin{array}{c}59,9-\mathrm{ke} \\
\text { bawah }\end{array}$ & - & 0 \\
\hline \multicolumn{5}{c}{ Jumlah } \\
\hline
\end{tabular}

Dari tabel 3 dapat diketahui bahwa sebanyak 44 mahasiswa telah mecapai nilai di atas 70 dan tidak ada mahasiswa yang memperoleh nilai di bawah nilai 70 atau B. Ada 22,7\% mahasiswa yang memperoleh nilai A dan ada $77,3 \%$ mahasiswa memperoleh nilai B. Sehingga dapat disimpulkan bahwa model pembelajaran Kooperatif Tipe Team Games Tournament telah meningkatkan hasil belajar passing bawah bola voli mahasiswa.

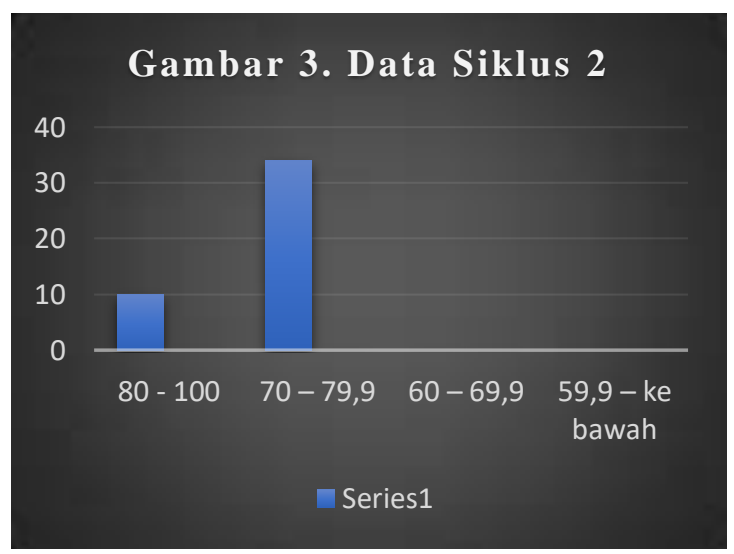

Dari data-data di atas telah diketahui bahwa model pembelajaran Kooperatif Tipe Team Games Tournament dapat meningkatkan hasil belajar passing bawah mahasiswa pada mata kuliah bola voli. Hal ini telah sesuai dengan tujuan dari pembelajaran tipe team games tournament yang bertujuan untuk setiap tim mampu menyelesaikan tugas dalam periode tertentu (Meyer et al., 2019).

Data menunjukan bahwa pada pra siklus ada 15,9\% mahasiswa yang telah mecapai nilai $70 \mathrm{ke}$ atas atau nilai $\mathrm{B}$. 
Kemudian pada akhir siklus 1 pendidikan jasmani dan kesehatan. menunjukkan adanya peningkatan nilai dari mahasiswa yaitu menjadi $29,5 \%$ mahasiswa yang telah mencapai nilai 70 . Dan di akhir siklus 2 ternyata sudah $100 \%$ mahasiswa memperoleh nilai 70 ke atas atau B.

Sehingga dari data ini dapat disimpulkan bahwa pembelajaran dengan model kooperatif tipe team games tournamet dapat meningkatkan hasil belajar passing bawah mahasiswa pada mata kuliah bola voli. Hal ini telah sesuai dengan pendapat dari (Ashworth, S. Mosston, 2018) model pembelajaran kooperatif akan memberikan peningkatan pada domain psikomotor, afektif dan kognitif pada mahasiswa. Melalui pembelajaran berkelompok mahasiswa mampu saling memberikan masukan dan evaluasi terhadap teman sehingga terjadi diskusi yang membangun (Ashworth, S. Mosston, 2018). Melalui pembelajaran berkelompok maka aktifitas sosial mahasiswa juga menjadi tumbuh dan dapat meningkatkan kesehatan mental pada mahasiswa (Ohrnberger et al., 2017), yang berimbas pada peningkatan semangat belajar mahasiswa. Maka berdasarkan hasil penelitian ini model pembelajaran kooperatif dengan tipe team games tournamet dapat digunakan untuk meningkatkan kemampuan psikomotor, kognitif, dan affektif mahasiswa

\section{Kesimpulan}

Setelah dilaksanakan penelitian ini maka dapat disimpulkan bahwa model pembelajaran kooperatif tipe team games tournamet memberikan dampak positif terhadap peningkatan hasil belajar passing bawah bola voli pada mata kuliah bola voli II mahasiswa semester ganjil program studi pendidikan jasmani FKIP UNIB.

\section{Ucapan Terima Kasih}

Penelitian ini dapat dilaksanakan berkat dana hibah penelitian dari FKIP Universitas Bengkulu, penulis mengucapkan terimakasih atas kepercayaan FKIP Universitas Bengkulu untuk mandat penelitian yang telah diamanahkan

\section{Daftar pustaka}

Ashworth, S. Mosston, M. (2018). Teaching Physical Education. Sara Ashworth.

Gall, M. D., Gall, J. P., \& Borg, W. R. (2003). Meredith D. Gall, Walter R. Borg, Joyce P. Gall - Educational Research_An Introduction (7th Edition)-Allyn \& Bacon (2003).pdf (pp. 569-575).

Kanca, I. N. (2017). Pengembangan Profesionalisme Guru Penjasorkes. Seminar Nasional Profesionalisme 
Tenaga Profesi PJOK, Pendidikan Olahraga Pascasarjana UM, Abad 21, 1-14.

Malik, A. A., \& Rubiana, I. (2019). Kemampuan Teknik Dasar Bola Basket: Studi Deskriptif Pada Mahasiswa. Journal of SPORT (Sport, Physical Education, Organization, Recreation, and Training), 3(2), 79-84. https://doi.org/10.37058/sport.v3i2.12 $\underline{38}$

Masi, P. W., \& Wasak, M. R. P. (2020). Improving Learning Outcomes of Student's Volleyball Arbitration using the Team Games Tournament Learning Model. JUARA: Jurnal Olahraga, 5(1), 83-92. https://doi.org/10.33222/juara.v5i1.81 $\underline{8}$

Metzler, M. W. (2017). Intructional Model For Physical Education. Allyn Bacon.

Meyer, O. A., Omdahl, M. K., \& Makransky, G. (2019). Investigating the effect of pre-training when learning through immersive virtual reality and video: A media and methods experiment. Computers and Education, 140(December 2018), 103603.

https://doi.org/10.1016/j.compedu.20 $\underline{19.103603}$
Miller, D. K. (2010). Measurement by the Physical Educator Why and How.

Mustafa, P. S., \& Dwiyogo, W. D. (2020). Kurikulum Pendidikan Jasmani, Olahraga, dan Kesehatan di Indonesia Abad 21. JARTIKA Jurnal Riset Teknologi Dan Inovasi Pendidikan, $3(2)$, 422-438.

https://doi.org/10.36765/jartika.v3i2.2 $\underline{68}$

Ohrnberger, J., Fichera, E., \& Sutton, M. (2017). The relationship between physical and mental health: A mediation analysis. Social Science and Medicine, 195(November), 4249.

https://doi.org/10.1016/j.socscimed.2 $\underline{017.11 .008}$

Oktariana, D., \& Hardiyono, B. (2020). Pengaruh Daya Ledak Otot Lengan, Daya Ledak Otot Tungkai Dan Kekuatan Otot Perut Terhadap Hasil Smash Bola Voli Pada Siswa SMK Negeri 3 Palembang. Journal Coaching Education Sports, 1(1), 1324.

https://doi.org/10.31599/jces.v1i1.82

Pujianto, D., \& Insanistyo, B. (2013).

Dasar Dasar Penelitian Pendidikan Jasmani (First). FKIP Universitas Bengkulu.

Suhesti Herin, M. (2020). Studi Minat Mahasiswa Program Studi Pendidikan 
Upaya Meningkatkan Hasil Belajar Passing Bawah Bola Voli Melalui Model Pembelajaran Kooperatif Tipe Team Games Tournament

E-ISSN: 2722-3450 P-ISSN: 2775-3808

Kepelatihan Olahraga Terhadap

Senam Aerobik. Jurnal Patriot, 2(1),

278-290.

https://doi.org/10.24036/patriot.v2i1.

$\underline{520}$ 